\title{
INFLUENCE OF SPATIALLY VARIABLE INSTRUMENT NETWORKS ON CLIMATIC AVERAGES
}

\author{
C. J. Willmott and S. M. Robeson
}

Center for Climatic Research, Department of Geography, University of Delaware

\author{
J. J. Feddema
}

Department of Geography, University of California, Los Angeles

\begin{abstract}
Instrument networks for measuring surface air temperature $(T)$ and precipitation $(P)$ have varied considerably over the last century. Inadequate observing-station locations have produced incomplete, uneven, and biased samples of the spatial variability in climate and, in turn, terrestrial and global scale averages of $T$ and $P$ have been biased. New high-resolution climatologies [Legates and Willmott, 1990a; 1990b] are intensively sampled and integrated to illustrate the effects of these nontrivial sampling biases. Since station networks may not represent spatial climatic variability adequately, their ability to represent climate through time is suspect.
\end{abstract}

\section{Introduction}

Increasing dependence of the world economy on climateinfluenced renewable resources (e.g., crops) has heightened our interests in climate, climatic variability and climatic forecasting. In recent years, general circulation or global climate models (GCMs) have simulated dramatic climatic change scenarios, intensifying scientific interest as well as economic and social concerns among the public and government. Efforts to verify or refute GCM prognostications have provided new impetus for climatologists to examine the instrumental record for evidence of climatic change. Within this paper, we focus on how well the instrumental record represents areally averaged climate and climatic variability. While a number of climatic variables are measured routinely, shelter-height air temperature and precipitation are examined since they have been the most extensively sampled in both space and time. How well temperature and precipitation station networks represent spatial variability is of particular concern because ill-conditioned networks can and have injected bias into spatial averages of climate.

From a climatological standpoint, the instrumental record is both incomplete and uneven. It is incomplete in that there are few variables for which there is sufficient large-scale spatial and temporal coverage for us to make confident statements about climatic variability. It is uneven in several respects. Spatial and temporal variability, for example, are better resolved for the recent past and for certain regions, such as North America, Europe, and India (Figure 1). Overviews of the historical (instrumental) record [Ellsaesser et al., 1986] usually summarize the available instrumental data as well as what can be inferred from those data. Such reviews have focused on how accurately

\section{Copyright 1991 by the American Geophysical Union.}

Paper number 91GL02844

0094-8534/91/91GL-02844\$03.00

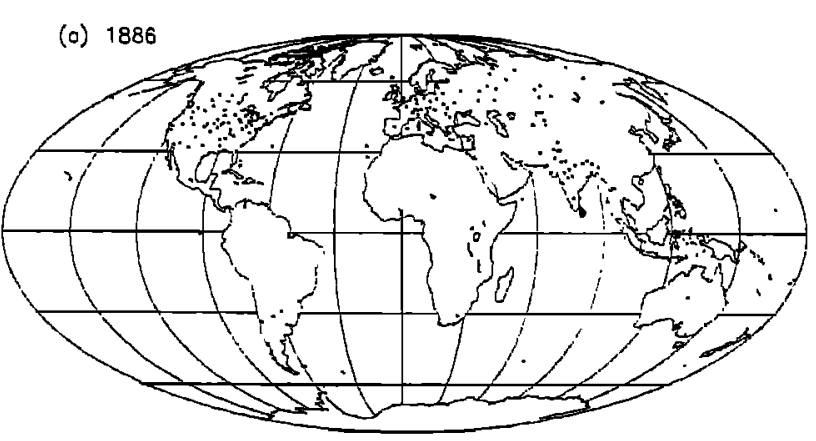

(b) 1920
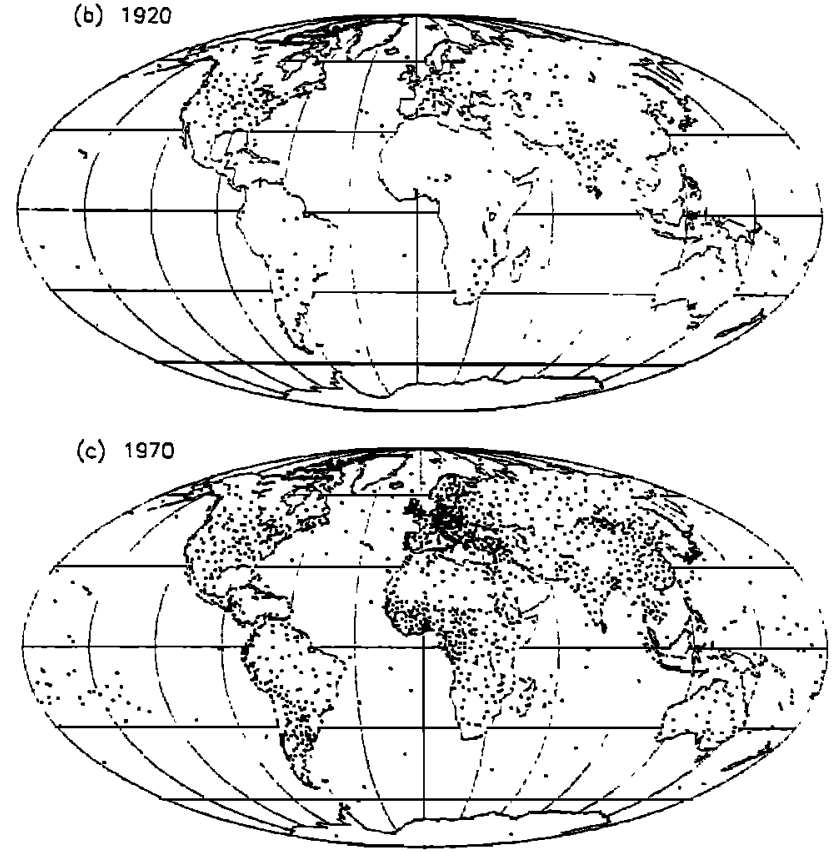

Fig. 1. Spatial distributions of air temperature stations in the NCAR surface station climatology for three selected years: (a) 1886, (b) 1920, and (c) 1970. Equal area Molleweide projection allows comparison of station densities between regions.

or precisely the instrumental record represents climate at the measurement (station) locations, the most commonly available variables, and the temporal variability that can be detected in the instrumental record. Documented errors that affect climatic data include: changes or discrepancies in observing practices [Mitchell, 1953; Karl et al., 1986; Schaal and Dale, 1977], movement and siting of stations [Mitchell, 1953; Quinlan et al., 1987], changes in the local environment [Mitchell, 1953; Karl and Jones, 1989; Kukla et al., 1986], and problems in the way that time-averages are constructed at the station locations [Mitchell, 1953; 
Edwards, 1987]. Whether the available station networks can faithfully represent areas (particularly large areas) has been incompletely examined. Tacit neglect of spatial representativeness problems by climatologists is illustrated by the paucity of maps showing pertinent station networks, station densities, or spatial biases [Ellsaesser et al., 1986].

\section{Terrestrial Air Temperature}

Of all climatic elements, mean air temperature is the most commonly used to characterize the overall climate. Although much attention has been paid to errors at individual temperature stations, perhaps even more uncertainty lies in the uneven distribution of stations and how this distribution has changed through time. Data contained in the NCAR surface station climatology [Spangler and Jenne, 1988] commonly form the core of global temperature change research [Jones et al., 1986; Hansen and Lebedeff, 1987]. While the NCAR archive was created so that spatial coverage was as uniform as possible, clearly both the number and distribution of stations change throughout the period of record (Figures 1 and 2).

To examine the effects of uneven station distributions, the yearly NCAR temperature station networks are evaluated using a high-resolution (17,986 terrestrial stations) climatology [Legates and Willmott, 1990a]. The ability of each yearly NCAR temperature network to represent terrestrial-scale variability is evaluated by sampling from the high-resolution field at the NCAR station locations, interpolating to a regular grid, and numerically integrating to obtain a terrestrial average (Figure 2). The interpolations are made using a spherically-based, weighted-average algorithm [Willmott et al., 1985] that is reliable [Bussiéres and Hogg, 1989]. Ideally, temperatures sampled at NCAR station locations should produce nearly the same terres-

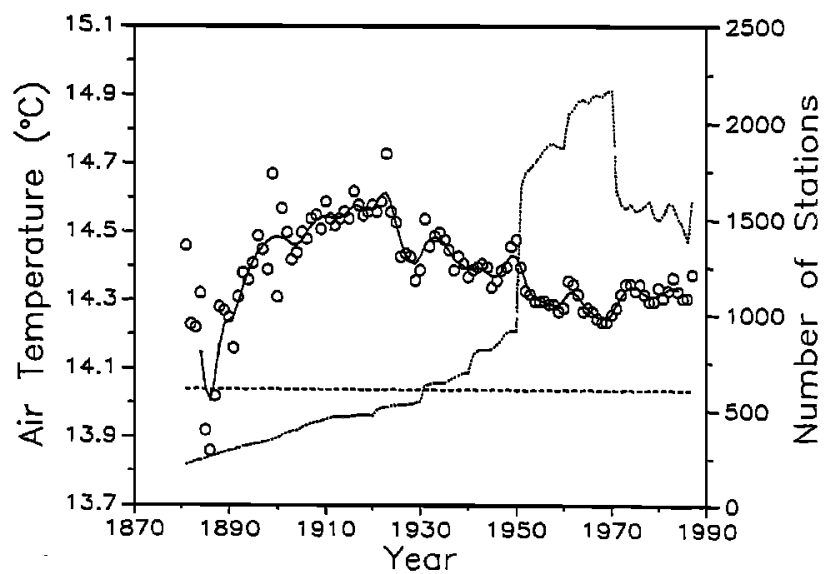

Fig. 2. Seven point Gaussian filter (solid line) applied to annual average terrestrial (excluding Antarctica and Greenland) air temperature estimates (circles) computed (interpolated and spatially averaged) from samples of a high-resolution climatology [Legates and Willmott, 1990a]. Sample points were the yearly station locations in the NCAR surface station climatology. Total number of NCAR temperature stations also is given (dotted line). A best estimate of the 'true' value of terrestrial average air temperature (using all of the stations in the climatology) is shown as the horizontal dashed line. trial mean as that obtained from the entire high-resolution climatology; however, marked discrepancies occur. Early in the record (1880s to 1920s), when less than 500 NCAR stations are available, estimates of terrestrially averaged temperature are highly variable and differ from the 'true' value (the horizontal dashed line in Figure 2) by as much as $0.6^{\circ} \mathrm{C}$. Later in the record, the estimates appear to approach an equilibrium value that is about $0.2^{\circ} \mathrm{C}$ higher than the 'true' average.

Most studies of global temperature change do not explicitly address the problems of uneven spatial sampling. However, in a study Northern Hemisphere temperature change, using an augmented NCAR data set, an attempt to estimate the effects of incomplete spatial coverage was made [Jones et al., 1986]. Instead of varying the station locations and keeping the underlying field fixed (as we have done), an examination of the difference between a fixed grid and a time-variable grid was made, while the station locations and temperature data also changed through time. Temperature deviations from station averages, rather than temperature itself, also were used. Although these differences make direct comparison with our results difficult, large variability $\left(>0.5^{\circ} \mathrm{C}\right.$ ) occurs early in the time series of Jones et al. [1986] as well.

\section{Terrestrial Precipitation}

Precipitation is probably the most extensively sampled climate variable. The number of raingages worldwide, for instance, likely exceeds 120,000 [Mintz, 1981] while monthly averages are available for well over 24,000 terrestrial stations [Legates and Willmott, 1990b]. In spite of numerous observations, station location bias still produces marked over- or underestimates of regional (and ultimately global) averages of precipitation. As with air temperature stations, precipitation gages tend to be located near human settlements, with high concentrations of gages in Europe, North America, India, and Japan. Few gages are located in the deserts or mountain regions.

Re-sampling again is used to illustrate the effects of uneven station networks on large-scale spatially averaged precipitation. A high-resolution annual mean precipitation field [Legates and Willmott, 1990b] is used to represent the 'true' spatial variability in precipitation. Numerical (spatial) integration of the annual average field can be thought of as the 'real' globally averaged rate of precipitation. As before, the ability of each yearly NCAR raingage network to represent terrestrial average precipitation can be examined by sampling from the 'true' field at the gage locations, interpolating to a regular grid [Willmott et al., 1985] and then numerically integrating to obtain estimates of spatially averaged precipitation. Yearly NCAR networks again are of interest because they have formed the bases of several studies of temporal variability in spatially averaged precipitation statistics [Bradley et al., 1987; Diaz et al., 1989].

Raingage networks within the NCAR archive are highly variable from year to year (Figure 3). Sparse station networks, particularly in the late 1800's to the late 1920's, produce sizable overestimates of terrestrially averaged precipitation $\left(\tilde{P}_{T}\right)$. Losses of important stations in Oceania during World War II lead to underestimation of $\tilde{P}_{T}$ in the 


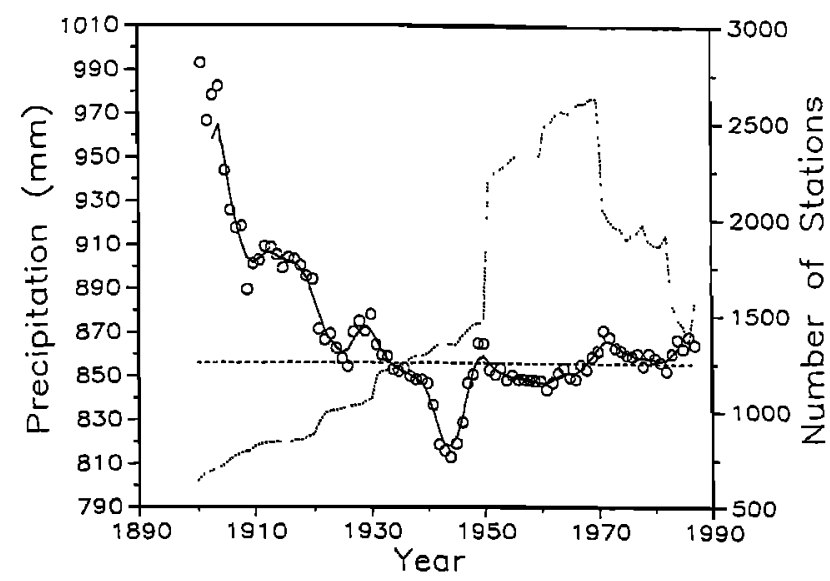

Fig. 3. As in Figure 2, except the variable of interest is annual average gage-corrected precipitation ( $\mathrm{mm} /$ year) from Legates and Willmott [1990b].

1940's. From 1950 to the present, the NCAR networks adequately resolve $\bar{P}_{T}$, although (in part) this is due to offsetting regional over- and underestimates. Since these network-induced errors are nontrivial, they may obscure the identification of real climatic change within the raingage record.

\section{Conclusions}

Evaluation of climate and climatic change from the instrumental record is subject to several biases. Problems associated with instrumental bias (measurement error, instrument exposure changes, temporal sampling bias, urban heating effects) have received much attention in recent years. Our analyses, in addition, show that the uneven spatial coverage of temperature and precipitation networks has introduced marked variability and bias into the large-scale climatic record.

Acknowledgements. Fruitful discussions and collaboration with David Legates (University of Oklahoma) regarding the influence of station networks on spatially averaged climatic variables are most appreciated. Financial support for this research was made available by the National Aeronautics and Space Administration through grants NAG5853 and NAGW-1884.

\section{References}

Bradley, R. S., H. F. Diaz, J. K. Eisheid, P. D. Jones, P. M. Kelly, and C. M. Goodess, Precipitation fluctuations over Northern Hemisphere land areas since the mid-19th century," Science, 237, 171-175, 1987.

Bussiéres, $N$. and W. Hogg, The objective analysis of daily rainfall by distance weighting schemes on a mesoscale grid, Atmosphere Ocean, 27, 521-541, 1989.

Diaz, H., R. S. Bradley, and J. K. Eischeid, Precipitation fluctuations over global land areas since the late 1800's, Journal of Geophysical Research, 94, 1195-1210, 1989.

Edwards, H. B., Sampling theory applied to measurement and analysis of temperature for climate studies, Journal of Climate and Applied Meteorology, 26, 731-736, 1987.

Ellsaesser, H. W., M. C. MacCracken, J. J. Walton, and
S. L. Grotch, Global climatic trends revealed by the recorded data, Reviews of Geophysics, 24, 745-792, 1986.

Hansen, J. and S. Lebedeff, Global trends of measured surface air temperature, Journal of Geophysical Research, 92, 345-413, 1987.

Jones, P. D., S. C. B. Raper, R. S. Bradley, H. F. Diaz, P. M. Kelly, and T. M. L. Wigley, Northern hemisphere surface air temperature variations: 1851-1984, Journal of Climate and Applied Meteorology, 25, 161-179, 1986.

Karl, T. R., C. N. Williams, Jr., P. J. Young, and W. M. Wendland, A model to estimate time of observation bias associated with monthly mean maximum, minimum, and mean temperatures for the United States, Journal of Climate and Applied Meteorology, 25, 145-160, 1986.

Karl, T. R. and P. D. Jones, Urban bias in area-averaged surface air temperature trends, Bulletin of the American Meteorological Society, \%0, 265-270, 1989.

Kukla, G., J. Gavin, and T. R. Karl, Urban warming, Journal of Climate and Applied Meteorology, 25, 1265-1270, 1986.

Legates, D. R. and C. J. Willmott, Mean seasonal and spatial variability in global surface air temperature, Theoretical and Applied Climatology, 41, 11-21, 1990a.

Legates, D. R. and C. J. Willmott, Mean seasonal and spatial variability in gauge-corrected, global precipitation, International Journal of Climatology, 10, 111-127, 1990b.

Mintz, Y., A brief review of the present status of global precipitation estimates, in Atlas, D. and O. W. Theile (eds.) Report of the Workshop on Precipitation Measurements from Space, NASA Goddard Space Flight Center, Greenbelt, MD, p. 1, 1981.

Mitchell, J. M., Jr., On the causes of instrumentally observed secular temperature trends, Journal of Meteorology, 10, 244-261, 1953.

Quinlan, F. T., T. R. Karl, and C. N. Williams, Jr., United States historical climatology network serial temperature and precipitation data, NDP-019. Carbon Dioxide Information Analysis Center, Oak Ridge National Laboratory, 1987.

Schaal, L. A. and R. F. Dale, Time of observation bias and 'climate change,' Journal of Applied Meteorology, 16, 215-222, 1977.

Spangler, W. M. L. and R. L. Jenne, World Monthly Surface Station Climatology, National Center for Atmospheric Research, Scientific Computing Division, 14pp, 1988.

Willmott, C. J., C. M. Rowe, and W. D. Philpot, Smallscale climate maps: A sensitivity analysis of some common assumptions associated with grid-point interpolation and contouring, American Cartographer, 12, 5-16, 1985.

C. J. Willmott and S. M. Robeson, Center for Climatic Research, Department of Geography, University of Delaware, Newark DE 19716.

J. J. Feddema, Department of Geography, University of California, Los Angeles CA 90024.

(Received July 18, 1991;

Revised September 18, 1991;

Accepted October 17, 1991) 